\title{
Heart failure and cerebral ischemia
}

\author{
Tamer Sayın and Çetin Erol
}

\author{
Ankara University, School of Medicine, Department of Cardiology, Ankara, Turkey
}

Corresponding Author:

Çetin Erol, Professor, MD, e-mail: ctnerol@yahoo.com

Heart failure patients may have impaired cerebral autoregulation and regional cerebral blood flow abnormalities. Predisposition to thromboembolic complications occur because of dilated chambers and abnormal blood flow, abnormal vessel/chamber lining and abnormal blood particles in heart failure patients. Epidemiological and clinical studies document an increased rate of thromboembolic complications in heart failure. Well known/accepted indications of oral anticoagulation therapy to prevent thromboembolic events are co-existence of atrial fibrillation/flutter, intracardiac thrombi and a history of a thromboembolic event. Other than a co-existence of coronary artery disease and heart failure, antiplatelet agents should not be used in heart failure patients to prevent ischemic stroke. How and who to treat/prevent a thromboembolic event in patients with heart failure and sinus rhythm is a hot topic. Up to date, clinical studies of treatment with oral anticoagulant agents-mainly warfarin and recently rivaroxaban vs antiplatelet agents or placebo could not meet their primary outcome related with morbidity/mortality. In some of these studies, decreased rate of ischemic strokes were offset by increased major hemorrhage.

Keywords: heart failure, cerebral ischemia, stroke

\section{Cerebral blood flow, autoregulation mechanisms, heart failure}

Weight of the brain is only approximately $2 \%$ percent of our body while its metabolic rate accounts close to $20 \%$ of the whole body (1). Despite such a high metabolic rate the amount of intracellular glycogen in the brain is low therefore a stable supply of cerebral blood flow (CBF) is critical to maintain normal brain functions. CBF is regulated by both local and systemic mechanisms (2).

The brain is far less tolerant to fluctuations in blood flow because of its dependence on aerobic metabolism and constraints imposed by bipedal posture on blood supply (3). Studies have shown that brain perfusion is maintained and regulated by the help of three mechanisms: neurovascular coupling, cerebral vasoreactivity and cerebral autoregulation.

\section{Neurovascular Coupling}

Regional flow differences, for differing functional activity of brain regions so as to compensate the increased metabolic demand of the specific region is called neu- rovascular coupling. Alterations in this mechanism can impair the brain vasculature to divert sufficient blood flow to active regions causing neural dysfunction $(3,4)$. Astrocytes are in direct contact with endothelial cells on the vascular smooth muscle and they can release vasodilatory substances as needed (5).

\section{Cerebral Vasoreactivity}

Cerebral vasoreactivity, another component of cerebrovascular control is the high sensitivity of cerebral vasculature to changes in arterial $\mathrm{CO}_{2}$ and oxygen $\left(\mathrm{O}_{2}\right)$ levels. Hypercapnia causes vasodilation and an increase in flow while hypocapnia leads to vasoconstriction. So, vasodilatation in response to hypercapnia clears $\mathrm{CO}_{2}$ off the brain circulation and conversely, vasoconstriction induced by hypocapnia attenuates the fall in brain $\mathrm{pH}$ (3).

\section{Cerebral Autoregulation}

Third mechanism, cerebral autoregulation helps to counteract fluctuations in systemic arterial pressure that can occur in daily activities. For instance, without effective cerebral autoregulation, sudden upright pos- 
ture could result in as much as a $50 \%$ drop in systolic blood pressure and vasovagal syncope. There are strong data to support the role of autonomic nervous system in cerebrovascular regulation (3).

Using transcranial Doppler and magnetic resonance flow/perfusion studies, there are data indicating that even mild heart failure patients may have impaired dynamic cerebral autoregulation and regional perfusion abnormalities $(6,7)$.

\section{Heart failure as a risk factor for stroke: epidemiology}

Heart failure (HF) is the second strongest independent risk factor for stroke after atrial fibrillation (AF) (8). Interestingly, a complex relation exists between $\mathrm{HF}$ and $\mathrm{AF}$, for both, causing a tendency to other's occurrence and a poorer clinical scenario, with an increased ischemic stroke risk when added to each other. An increased risk of venous thromboembolism, cardio-embolic stroke and sudden death occurs in approximately $30 \%$ of $\mathrm{HF}$ patients (9). Interestingly, in many studies reduced or preserved heart failure discrimination hasn't been reported but it seems likely that more severely depressed reduced ejection fraction possesses further risk just like accompanying pulmonary hypertension and right heart failure (9). In a population based 30-year cohort study from Denmark incident HF patients were compared with agesex-comorbidity matched general population controls. In this study, HF was associated with increased short and long term risk of all stroke subtypes suggesting that $\mathrm{HF}$ is a potent and persistent risk factor for stroke. During 31 days and 30 years risk of stroke were 1.5 to 2.1 fold for ischemic stroke, 1.4 to 1.8 fold for intracranial hemorrhage and 1.1 to 1.7 fold for subarachnoid hemorrhage (10). Importantly, in this study, authors take AF into consideration during follow-up and their analysis which makes the study more robust and valuable.

Among patients presenting with stroke or peripheral thromboembolism the prevalence of HF, especially $\mathrm{HF}$ with reduced ejection fraction (HRrEF) or left ventricular systolic dysfunction (LVSD) is quite frequent. About $14 \%$ of patients with stroke have HF and approximately $20 \%$ of the stroke patients have some evidence LVSD (ejection fraction-EF $<50 \%)(11,12)$. Data on thromboembolic risk in HF from large epidemiological studies is somewhat problematic in terms of reporting/discriminating about HFrEF and HF with preserved ejection fraction. Another confounding point is reporting about concomitant $\mathrm{AF}$, not all studies deal with this important issue (9).

In the Rotterdam Study, among 7546 patients aged $>55$ years who were followed for 10 years, risk of ischemic stroke was increased more than fivefold in the first month of diagnosis of HF but this risk of ischemic stroke attenuated over time and returned to normal after six months
(13). This finding contrasts with the Danish study reporting consistent and persistent risk throughout 30 years of follow up (10). Patients with HF also have a high rate of stroke recurrence and mortality after stroke $(14,15)$.

A well-known association exists between HF and venous thromboembolism (VTE), a two fold increase of VTE occurs with important outcomes for prognosis and death (16).

Annual stroke rates of $1.1 \%-4.6 \%$ have been reported in HF trials, however many of these analysis included some patients with AF (9). The Cooperative North Scandinavian Enalapril Survival Study (CONSENSUS) reported the highest annular cerebrovascular event rate of \% 4.6 among HF trials, but this trial included patients with severe LVSD and a high prevalence of concomitant AF (17). An analysis of Vasodilator Heart Failure Trials I-II (V-HeFT I and II) reported an incidence $2.7 \%$ and $2.1 \%$ of thromboembolic events per year in patients who were not using oral anticoagulation (18).

An analysis from the SCD-HeFT trial (Sudden Cardiac Death in Heart Failure Trial) of patients with NYHA class II and III without AF reported a 4 year incidence of thromboembolism (mostly strokes) $4 \%$. Rate of subgroups were $2.6 \%$ for patients randomised to amiodarone, 3.25 for patients randomized to an internal cardioverter defibrillator (ICD), and $6 \%$ for patients randomized to placebo (19). Of note, decreasing left ventricular ejection fraction (LVEF) was a significant predictor of thromboembolism (HR: 0.82; 95\% Cl: 0.69-0.97 per $5 \%$ increase in EF).

In an analysis of data on warfarin use in SOLVD study (Studies of Left Ventricular Dysfunction), the authors found that warfarin use was independently associated with significant reduction in all-cause mortality (adjusted HR: $0.76,95 \%$ Cl: $0.65-0.89 ; p=0.0006$ ) and in the risk of death or hospital admission for HF (HR: 0.82, 95\% Cl: 0.72-0.93, $p=0.0002$ ). Reduction in risk was not significantly influenced age, NYHA functional class or etiology of HF, EF, AF (20).

There are limited data on the rate of stroke in patients with HFpEF. Some data from post-hoc analysis of large clinical HFpEF studies document similar rates. For instance, the I-PRESERVE study (Irbesertan in Patiens with Heart Failure and Preseved Ejection Fraction) reported an annual rate of stroke as $0.8-0.9 \%$, additionally $9 \%$ of all deaths were because of stroke (21). In the CHARM-Preserved study (Candesartan in Heart Failure Assessment of Reduction in Mortality and Morbidity) rate of fatal and non-fatal stroke was unrelated to EF (EF $<22 \% 1.2 \%$, EE 23-32\% 1.4\%, EF 33-42 1.4\%, EF $43-521.3 \%$, and $E F>52 \% 1.5 \%$ ).

\section{Pathophysiology}

Increased rates of thrombotic complications in patients with HF has well known pathophysiological basis. Pre- 
cipitation to thrombogenesis is related with a combination of abnormal blood flow, abnormalities in the vessel wall and abnormalities in the blood constituents itselfthe Virchow's triad (22).

Especially, in the setting of reduced LVEF, dilated chambers and a marked decrease in systolic function and a tendency for stasis of blood and thrombosis occurs in heart chambers. Blood flow abnormalities is common in dilated aneurysmatic heart chambers. In patients with large anterior myocardial infarctions- developing an apical aneurysm it is widely accepted to use anticoagulant therapy for 3 months post myocardial infarction (MI) (9).

Another component of the Virchow triad is vessel wall. Around half to two thirds of patients with HFrEF have athero-thrombotic disease, underlying endothelial damage/dysfunction might precipate thromboembolic complications. In patients with HF impaired synthesis of endothelium derived nitric oxide may promote monocyte and platelet adhesion to endothelium (23). Biological markers of endothelial dysfunction and rheologic markers of thrombogenecity-, a hypercoagulable state indicators such as von Willebrand factor, thrombomodulin, soluble e-selectin are found to be consistently elevated in patients with HF (24-26).

A high prevalence of anemia and iron deficiency is reported in patients with HF that may additionally predispose to thrombosis (27). Elevated levels of erythropoietin which is commonly found in anemic - iron deficient patients, iron deficiency related reactive thrombocytosis, increased platelet aggregation as a result of oxidative stress are the proposed components of iron deficient anemic patients' predisposition to thromboembolic events $(9,28)$.

\section{Heart failure and stroke: clinical evaluation}

It is quite common for the clinical cardiologist to be consulted by a neurologist for a stroke or transient ischemic attack (TIA) patient to evaluate the heart as a source of embolic phenomenon. In such a patient with non-valvular AF, the case is relatively easy- an apparent cause of cardiac embolism. If the patient has no sign and symptoms of heart disease, no hypertension, and no diabetes mellitus and if ECG and chest $x$-ray are normal, possibility of a cardiac embolic event is very low. Especially, for a cryptogenic stroke case in a young to middle aged patient, performing an echocardiography to evaluate for a patent foramen oval should be undertaken as well as a Holter rhythm study to exclude paroxysmal atrial fibrillation or flutter. For an undetermined etiology of stroke, it may be necessary to check for intrinsic hypercoagulability test.

In a systematic review of embolic stroke of undetermined source, the authors concluded that so as to define an embolic stroke as "undetermined source", there should be no major risk of cardioembolic source. In this review, major sources for cardioembolism are defined as follows; permanent or paroxysmal atrial fibrillation, sustained atrial flutter, intracardiac thrombus, prosthetic cardiac valve, atrial myxoma or other cardiac tumors, mitral stenosis, recent myocardial infarction ( $<4$ weeks), LVEF $<30 \%$, valvular vegetations or infective endocarditis (29).

Especially, for cryptogenic embolism a high index of suspicion for PAF is prudent. Although we lack direct studies from HF populations, one systematic review demonstrated that PAF may be documented in $5 \%$ of ischemic stroke patients using prolonged ECG recordings $(9,30)$.

\section{Imaging}

In an transthoracic echocardiographic (TTE) study, intracardiac thrombi would seem as echogenic, dense, heteregenous convex masses with clear margins. It can appear as sessile or pedinculated, locates close to thin dyskinetic ventricular segments or in the atrial appendage. Devices, tumors, vegetations, artefacts may resemble thrombi and a differential diagnosis should be made as needed. Intravenous agitated saline or transpulmonary contrast agents can help for diagnostic differentiation (31). So as to reduce cardioembolic risk anticoagulation is essential but age of the thrombus, echocardiographic appearance of an endothelized or mobility would affect treatment decisions and responsible clinician should proceed accordingly.

In some certain circumstances, a transesophageal echo (TEE) study may help to have additional diagnostic insights to TTE. TTE may be limited by suboptimal images (particularly in obese patients), restricted field for imaging cardiac apex and left atrial appendage. In a series of ischemic stroke patients the authors have performed TEE and the have explored thrombus in $25 \%$ of patients (32).

Other than a visible thrombus, well known potential cardioembolic sources are; catheter leads, central lines, prosthetic valves, patent foramen ovale, spontaneous echocontrast, thin mobile mitral strands, mitral stenosis, LV systolic and diastolic dysfunction and perhaps pulmonary vein ablation-isolation (33). In a study of ischemic stroke patients, patients with coronary artery disease (CAD), ECG evidence of ischemia or LVSD, large strokes, AF were more likely to have intracardiac thrombus on TOE (32). Thus, it is conceivable that clinical clues of heart disease and LV dysfunction on TTE may help the clinician to proceed with a TOE depending on the individual circumstances.

In some patients, especially for morbid obese and those with poor echo image quality ultrafast computed tomography or magnetic resonance (MR) imaging may be helpful to detect intracardiac thrombus since they are less operator dependent and have high spatial and temporal resolution with better tissue characterization. 
In one MR series, using gadolinium enhanced cardiac MR authors reported ventricular thrombi in $21 \%$ of patients with ischemic cardiomyopathy or prior MI. Of note, in less than half of patients with cardiac thrombus TTE was negative and in $5 \%$ of patients TTE gave false positive images (34). The difficulty with MR is that it's not widely available and expertise and experience is important.

\section{Heart failure - cerebral ischemia, prevention/treatment}

In HF, a clinical condition that is a predisposing factor for thromboembolic events, antithrombotic treatment could be expected to prevent thromboembolic events. However, in order to have a net risk/benefit ratio of prevention of thromboembolism vs major bleeding-intracranial hemorrhage we need relevant reliable data. Interestingly, many of the HFrEF patients due to CAD would already be receiving an antiplatelet agent, mainly acetylsalicylic acid for prevention of atherothrombotic complications of CAD, which might also help to prevent stroke. Making issues even more complex, for instance, for registry studies is acute coronary syndromes and or implantation of drug eluting stents which would require dual antiplatelet therapy that might also help prevention of ischemic strokes. As reviewed above, unnoticed PAF may be the cause of ischemic stroke, a possibly confounding variable for clinical studies. We don't have large, double blind, placebo controlled, prospective studies of HF patients in sinus rhythm to search for efficacy of antiplatelet agents in reducing ischemic stroke risk (9).

Comment of European Society of Cardiology (ESC) HF guidelines published in 2016 on oral anticoagulant and antiplatelet agents is as follows; no antiplatelet therapy other than patients with accompanying CAD whereas there is a substantial risk of gastrointestinal bleeding particularly in elderly patients, in patients with AF and venous thromboembolism oral anticoagulant agents should be used (35). Anticoagulant agents may potentially be considered for intracardiac thrombus, prolonged immobilization/bed rest and for patients accompanying right heart failure and pulmonary hypertension (9).

An important question that has been tried to be addressed by the medical community in the field is the issue "preventing stroke in heart failure patients with sinus rhythm". Recently, a systematic review and me-

Table 1. Baseline characteristics of patients with HF in sinus rhythm randomised to anticoagulation therapy or control

\begin{tabular}{|c|c|c|c|c|c|}
\hline Characteristics & WASH (37) & HELAS (38) & WATCH (39) & WARCEF (40) & COMMANDER-HF (41) \\
\hline Publication year & 2004 & 2006 & 2009 & 2012 & 2018 \\
\hline Study design & $\begin{array}{l}\text { Open label, } \\
\text { controlled }\end{array}$ & $\begin{array}{l}\text { Double blind } \\
\text { randomised placebo } \\
\text { controlled }\end{array}$ & $\begin{array}{l}\text { Double blind, } \\
\text { randomised, double } \\
\text { dummy controlled } \\
\text { for antiplatelet or } \\
\text { open label warfarin }\end{array}$ & $\begin{array}{l}\text { Double blind, } \\
\text { randomised, } \\
\text { double dummy } \\
\text { controlled trial }\end{array}$ & $\begin{array}{l}\text { Double blind, } \\
\text { randomised, placebo } \\
\text { controlled trial }\end{array}$ \\
\hline $\begin{array}{l}\text { Main inclusion } \\
\text { criteria }\end{array}$ & $\begin{array}{l}\text { HF requiring } \\
\text { diuretic }\end{array}$ & HF NYHA II-IV & $\begin{array}{l}\text { Symptomatic HF, } \\
\text { diuretic + ACEI } \\
>60 \text { days }\end{array}$ & HF NYHA I-IV & $\begin{array}{l}\text { HF } \leq 3 \text { months } \\
\text { duration, CAD, recent } \\
\text { WHF, elevated } \\
\text { natriuretic peptides }\end{array}$ \\
\hline $\begin{array}{l}\text { LVEF inclusion } \\
\text { criteria }\end{array}$ & $\leq 35 \%$ & $<35 \%$ & $\leq 35 \%$ & $\leq 35 \%$ & $\leq 40 \%$ \\
\hline Randomised (n) & 279 & 197 & 1587 & 2305 & 5022 \\
\hline $\begin{array}{l}\text { Therapies } \\
\text { evaluated }\end{array}$ & $\begin{array}{l}\text { Warfarin vs. } \\
\text { aspirin vs. no } \\
\text { antiplatelet }\end{array}$ & $\begin{array}{l}\text { Warfarin vs. placebo vs. } \\
\text { aspirin }\end{array}$ & $\begin{array}{l}\text { Warfarin vs. aspirin } \\
\text { vs. clopidogrel }\end{array}$ & $\begin{array}{l}\text { Warfarin vs. } \\
\text { aspirin }\end{array}$ & $\begin{array}{l}\text { Rivaroxaban vs. } \\
\text { placebo }\end{array}$ \\
\hline Target INR & $2-3$ & $2-3$ & $2.5-3$ & $2 .-3.5$ & NA \\
\hline $\begin{array}{l}\text { Aspirin dose } \\
\text { (mg/day) }\end{array}$ & 300 & 325 & 162 & 325 & NA \\
\hline Location & USA and UK & $\begin{array}{l}\text { Greece, Cyprus, } \\
\text { Yugoslavia, Romania, } \\
\text { Bulgaria, Poland and } \\
\text { Georgia }\end{array}$ & $\begin{array}{l}\text { USA, UK and } \\
\text { Canada }\end{array}$ & $\begin{array}{l}\text { North America, } \\
\text { Europe, } \\
\text { Argentina }\end{array}$ & $\begin{array}{l}\text { Europe, North } \\
\text { America, Latin } \\
\text { America, Asia- } \\
\text { Pacific, South Africa }\end{array}$ \\
\hline $\begin{array}{l}\text { Primary end } \\
\text { point }\end{array}$ & $\begin{array}{l}\text { Composite } \\
\text { outcome of } \\
\text { death, non-fatal } \\
\text { MI, non-fatal } \\
\text { stroke }\end{array}$ & $\begin{array}{l}\text { Composite of non-fatal } \\
\text { stroke, peripheral or } \\
\text { pulmonary embolism, } \\
\text { MI, rehospitalization, } \\
\text { WHF, ACM }\end{array}$ & $\begin{array}{l}\text { Composite of } \\
\mathrm{ACM}^{* *} \text {, non-fatal } \\
\text { MI, non-fatal stroke }\end{array}$ & $\begin{array}{l}\text { Time to first event } \\
\text { in a composite } \\
\text { end point of } \\
\text { ischemic stroke, } \\
\mathrm{ICH}, \mathrm{ACM}\end{array}$ & $\begin{array}{l}\text { Composite of ACM, } \\
\text { non-fatal MI and } \\
\text { non-fatal stroke }\end{array}$ \\
\hline
\end{tabular}


ta-analysis of randomized controlled trials on oral anticoagulation versus antiplatelet or placebo for stroke prevention in patients with HF and sinus rhythm was published (36). The authors focused on five studies, summarized in table 1. They concluded that oral anticoagulation is associated with a considerable reduction of stroke risk, which is offset by a significant risk in major bleeding. The authors calculated that for every 1000 patients treated with oral anticoagulation rather than antiplatelet or no antithrombotic treatment for 2.21 years, 13 strokes are prevented but 20 additional major hemorrhages occurred without significant decrease in death rates (36) (Table 1).

Beggs et al (42) recently performed a similar review and meta-analysis of anticoagulation therapy in heart failure and sinus rhythm. They also pointed out the same five clinical randomised trials to address the issue. These trials were the Warfarin/Aspirin Study in Heart Failure (WASH) trial (37), the HEart failure Long term Antithrombotic Study (HELAS) (38), the Warfarin and Antiplatelet Therapy in Chronic Heart Failure (WATCH) (39), Warfarin versus Aspirin in Reduced Cardiac Ejection Fraction (WARCEF) (40), Study to Assess the Effectiveness and Safety of Rivaroxaban in Reducing the Risk of Death, $\mathrm{MI}$, or Stroke in patients with HF and CAD Following an Episode of Decompensated HF (COMMANDER HF) (41). In this metaanalysis they found no effect on allcause mortality, no effect on nonfatal MI. There was no effect of anticoagulation therapy on (re)hospitalisation for HF. There was a significant decrease in non-fatal stroke which was offset by major hemorrhage.

COMMANDER HF (41) was the largest study in the meta-analysis performed by Beggs et al. Also, it was the only randomised trial with a non-vitamin $\mathrm{K}$ antagonist oral anticoagulant (NOAC) in the given context of HF-sinusal rhythm patients. CAD-HF patients received rivaroxaban $2.5 \mathrm{mg}$ bid or placebo in addition to their antiplatelet therapy. The primary outcome, a composite of first occurrence of death, stroke or MI was negative.

\section{Heart Failure - Sinus Rhythm - Risk of Stroke: Need for Identifying a Higher Stroke Risk Subgroup?}

Current data, in preventing stroke, using oral anticoagulants, in HF with sinus rhythm without well-known compelling indications (previous thromboembolism, intracardiac thrombus etc.) is negative. Some authors advocate using some kind of risk models to identify higher risk patients so that use of oral anticoagulans would be justified (9). A nationwide prospective cohort study tried to address this issue (43). The authors used well-known $\mathrm{CHA}_{2} \mathrm{DS}_{2}$ VASc stroke risk prediction model of AF to predict ischemic stroke, thromboembolism, and death in patients with heart failure with or without atrial fibrillation. They concluded that among patients with incident $\mathrm{HF}$ with or without $\mathrm{AF}$, the $\mathrm{CHA}_{2} \mathrm{DS}_{2}$ VASc score was associated with risk of ischemic stroke, thromboembo- lism and death. At high $\mathrm{CHA}_{2} \mathrm{DS}_{2}$ VASc scores $(\geq 4)$ absolute risk of thromboembolism was high regardless of presence of AF. However, they also found that predictive accuracy was modest and they claimed that clinical utility of $\mathrm{CHA}_{2} \mathrm{DS}_{2}$ VASc score in patients with HF needs to be determined.

\section{Conclusion}

Cerebral blood flow abnormalities occur in HF. HF is a major risk factor for thromboembolic events. Use of oral anticoagulants in HF are justified in their well-known indications namely AF, history of a thromboembolic event and intracardiac thrombi.

\section{REFERENCES}

1. Elia M. Organ and tissue contribution to metabolic rate. New York: Raven Press, LtD; 1992.

2. Tarumi T, Zhang R. Cerebral blood flow in normal aging adults: Cardiovascular determinants, clinical implications and aerobic fitness. J Neurochem 2018; 144(5): 595-608. https://doi.org/10.1111/jnc.14234 3. Ozturk ED, Tan CA. Human cerebrovascular function in health and disease: insights from integrative approaches. Journal of Physiological Anthropology 2018; 37: 4-11.

4. Girouard H, ladecola C. Neurovascular coupling in the normal brain and in hypertension, stroke and Alzheimer disease. J Appl Physiol 2006; 100 (1): 328-35.

https://doi.org/10.1152/japplphysiol.00966.2005

5. Jakovcevic D, Harder DR. Role of astrocytes in matching blood flow to neuronal activity. Curr Top Dev Biol 2007; 79: 75-97.

https://doi.org/10.1016/S0070-2153(06)79004-4

6. Erkelens CD, Haye van der Wal, Bauke M. De Jong et al. Dynamics of cerebral blood flow in patients with mild non ischaemic heart failure. European Journal of Heart Failure 2017; 19: 261-268.

https://doi.org/10.1002/ejhf.660

7. Caldas JR, Panerai RB, Haunton VJ, et al. Cerebral blood flow autoregulation in heart failure. Am J Physiol Regul Integr Comp Physiol 2017; 312: R108-R113. https://doi.org/10.1152/ajpregu.00361.2016 8. Appelros P, Nydevik I, Seiger A, et al. Predictors of severe stroke: influence of preexisting dementia and cardiac disorders. Stroke 2002; 33: 2357-62. https://doi.org/10.1161/01.str.0000030318.99727.fa

9. Lip GYH, Ponikowski p, Andreotti F, et al. Thromboembolism and antithrombotic therapy for heart failure in sinus rhythm. A joint consensus document from the ESC heart failure associationand the ESC working group on thrombosis. European Journal of Heart Failure 2012; 14: 681-95. https://doi.org/10.1093/eurjhf/hfs073.

10. Adelborg K, Szepligeti S, Sundboll J, et al. Risk of stroke in patients with heart failure. A population based 30 year cohort study. Stroke 2017; 48: 1161-68.

https://doi.org/10.1161/strokeaha.116.016022

11. Appelros P, Nydevik I, Vitanen M. Poor outcome after first ever stroke-predictors for death, dependency and recurrent stroke within the first year. Stroke; 2003: 34: 122-26.

https://doi.org/10.1161/01.str.0000047852.05842.3c

12. Hays AG, Sacco RL, Rundek T, et al. Left ventricular systolic dysfunction and the risk of ischemic stroke in a multiethnic population. Stroke; 2006: 37; 1715-19.

https://doi.org/10.1161/01.STR.0000227121.34717.40

13. Alberts VP, BosMJ, Koudstaal PJ, et al. Heart failure and the risk of stroke: the Rotterdam study.Eur J Epidemiol 2010; 25: 807-12. https://doi.org/10.1007/s10654-010-9520-y 
14. Petty GW, Brown RD Jr, Whisnant JP, et al. Survival and recurrence after first cerebral infarction: a poulation based in Rochester, Minnesota, 1975 through 1989. Neurology 1998; 50: 208-16.

https://doi.org/10.1212/wnl.50.1.208

15. Socco RL, Shi T, Zamanilo M, et al. Predictors of mortality and recurrence after hospitalized cerebral infarctionin an urban community: the Northern Manhattan Stroke study. Neurology 1994; 44: 626-34. https://doi.org/10.1212/wnl.44.4.626

16. Beemath A, Stein PD, Skaf E, et al. Risk of venous thromboembolism in patients hospitalized with heart failure. Am J Cardiol 2006: 98: 793-95. https://doi.org/10.1016/j.amjcard.2006.03.064

17. The CONSENSUS trial Study group. Effect of enalapril on mortality in severe heart failure. Results of theCooperative North Scandinavian Enalapril Survival Study (CONCENSUS). N Engl J Med 1987; 316: 1429-35. https://doi.org/10.1056/NEJM198706043162301 18. Dunkman WB, Johnson GR, Carson PE, et al. Incidence of thromboembolic events in congestive heart failure trial. The V-HeFT VA Cooperative Studies Group. Circulation 1993; 87(6 Suppl): V94-V101. 19. Freudenberger RS, Hellkamp A, Halperin JL, et al. Risk of thromboembolism in heart failure: an analysis from the Sudden Cardiac Death in Heart Failure Trial (SCD-HeFT). Circulation 2007; 115: 2637-41. https://doi.org/10.1161/CIRCULATIONAHA.106.661397 20. Al-khadra AS, salem DN, Rand WM, et al. Warfarin anticoagulation and survival: a cohort analysis from the Studies of Left Ventricular Dysfunction. J Am Coll Cardiol 1998; 31: 749-53.

https://doi.org/10.1016/s0735-1097(98)00006-0

21. Massie BM, Carson P, McMurray JJ, et al. I-PRESERVE investigators. Irbesertan in patients with heart failure and preserved ejection fraction. N Engl J Med 2008; 359: 2456-67.

https://doi.org/10.1056/NEJMoa0805450

22. Virchow R. GesammelteAbhandlungenzur WissenscfaftichenMedicine. Frankfurt Meidinger Sohn \& Co; 1856. pp. 219-732.

23. Fisher D, Rossa S, Landmesser U, et al. Endothelial dysfunction in patients with chronic is independently associated with increased incidence of hospitalization, cardiac transplantation or death. Eur Heart J 2005; 26: 65-69. https://doi.org/10.1093/eurheartj/ehi001

24. Gibbs CR, Blann AD, Watson RD, et al. Abnormalities of hemorheological, endothelial, and platelet function in patiens with chronic heart failure in sinus rhythm: effects of angiotensin-converting enzyme inhibitor and beta blocker therapy. Circulation 2001; 103: 1746-51. https://doi.org/10.1161/01.cir.103.13.1746

25. Chong AY, Freestone B, Patel Lim H, et al. Endothelial activation, dysfunction and damage in chronic heart failure and the relation to brain natriuretic peptide and outcomes. Am J Cardiol 2006; 97: 671-75. https://doi.org/10.1016/j.amjcard.2005.09.113

26. Alehagen $U$, Dahlstrom $U$, Linhahl TL, et al. Elevated $D$ dimer levels is an independent risk factorfor cardiovascular death in outpatients with symptoms compatible with heart failure. Thromb Homeost 2004; 92: 1250-58.

27. Jankowska EA, Rozentyrt P,Witkowska A, et al. Iron deficiency: an ominous sign in patients with systolic chronic heart failure. Eur Heart J 2010; 31: 1872-78. https://doi.org/10.1093/eurheartj/ehq158 28. Besarab A, Hörf WH, Silverberg D. Iron metabolism, iron deficiency, thrombocytosis and the cardiorenal anemia syndrome. Oncologist 2009; 14(Suppl 1): 22-33. https://doi.org/10.1634/ theoncologist.2009-S1-22

29. Hart RG, Catanese L, Kanjana SP, et al. Embolic stroke of un- determined source. A systematic review and clinical update. Stroke 2017; 48: 867-72. https://doi.org/10.1161/STROKEAHA.116.016414 30. Liao J, Khalid Z, Scallan C, et al. Non invasive cardiac monitoring for detecting paroxysmal atrial fibrillation or flutter after acute ischemic stroke : a systematic review. Stroke 2007; 38: 2935-40. https://doi.org/10.1161/STROKEAHA.106.478685

31. Mansencal N, Revault-d'Allonnes L, Pelage JP, et al. Usefulness of contrast echocardiography for assessment of intracardiac masses. Arc Cardiovas Dis 2009; 2009: 102: 177-83.

https://doi.org/10.1016/j.acvd.2008.12.007

32. Sen S, Laowatana S, Lima J, et al. Risk factors for intracardiac thrombus in patients with recent ischemic cerebrovascular events. J Neurol Neurosurg Psychiatry 2004; 75: 1421-25.

https://doi.org/10.1136/jnnp.2004.038687

33. Lee RJ, Bartzokis T, Yeoh TK, et al. Enhanced detection of intracardiac of cerebral emboli by transesophageal echocardiography. Stroke 1999; 22: 734-39. https://doi.org/10.1161/01.str.22.6.734

34. Mollet NR, Dymarkowski S, Volders W, et al. Visualization of ventricular thrombi with contrast enhanced magnetic imaging in patients with ischemic heart disease. Circulation 2002; 106: 2873-76. https://doi.org/10.1161/01.cir.0000044389.51236.91

35. Ponikowski P, Voors AA, Anker SD, et al. 2016 ESC guidelines for the diagnosis and treatment of acute and chronic heart failure. Eur Heart J 2016; 37(27): 2129-2200.

https://doi.org/10.1093/eurheartj/ehw128.

36. Ntaios G, Vemmos K, Lip GYH. Oral anticoagulation versus antiplatelet or placebo for stroke prevention in patients with heart failure and sinus rhythm: systematic review and metaanalysis of randomized controlled trials. International Journal of Stroke 2019; 14(9): 856-61. https://doi.org/10.1177/1747493019877296.

37. Cleland JG, Findlay I, Jafri S, et al. The Warfarin/Aspirin study in heart failure (WASH) : a randomised trial comparing antithrombotic strategies for patients with heart failure. Am Heart J 2004; 148: 157-64. https://doi.org/10.1016/j.ahj.2004.03.010.

38. Cokkinos DV, Haralabopoulos GC, Kostis JB, et al. Efficacy of antithrombotic therapy in chronic heart failure : the HELAS study. Eur J Heart Fail 2006; 8: 428-32.

39. Massie BM, Collins JF, Ammon SE, et al. Randomised trial of warfarin, aspirin and clopidogrel in patients with chronic heart failure: the Warfarin and Antiplatelet Therapy in Chronic Heart Failure (WATCH) trial. Circulation 2009; 119: 1616-24.

https://doi.org/10.1161/CIRCULATIONAHA.108.801753

40. Homma S, Thompson JL, Pullcino PM, et al. Warfarin and aspirin in patients with heart failure and sinus rhythm. N Engl J Med 2012; 366: 1859-69. https://doi.org/10.1056/NEJMoa1202299

41. Zannad F, Anker SD, Byra WM, et al. Rivaroxaban in patients with heart failure, sinus rhythm and coronary disease. N Engl J Med 2018; 379: 1332-42. https://doi.org/10.1056/NEJMoa1808848

42. Beggs SA, Rorth R, Gardner RS, et al. Anticoagulation therapy in heart failure and sinus rhythm : a systematic review and metaanalysis. Heart 2019; 105: 1325-34.

https://doi.org/10.1136/heartjnl-2018-314381

43. Melgaard L, Gorst-Rasmussen A, Lane DA et al. Assessment of the $\mathrm{CHA}_{2} \mathrm{DS}_{2}$ VASc score in predicting ischemic stroke, thromboembolism, and death in patients with heart failure with and without atrial fibrillation. JAMA 2015; 314(10): 1030-38.

https://doi.org/10.1001/jama.2015.10725 